\title{
La escritura de Mario Levrero como una cartografía autobiográfica y literaria, rioplatense y trasatlántica ${ }^{1}$
}

\author{
Mario César Islas Flores \\ Becario del Programa de Becas Posdoctorales en la UNAM \\ Universidad Nacional Autónoma de México, Ciudad de México, México \\ https://orcid.org/0000-0002-8076-6529 \\ islas flores@hotmail.com
}

\section{Resumen}

En este artículo, se realiza un análisis de la escritura autobiográfica de Mario Levrero (19402004) a partir de la categoría de espacialidad y la perspectiva teórica de Karl Schlögel. Consideramos que Apuntes bonaerenses, Diario de una canalla, El discurso vacío, La novela luminosa y Burdeos, 1972 constituyen una cartografía autobiográfica y literaria rioplatense y trasatlántica dentro de la obra levreriana en la medida en que las ciudades uruguayas de Montevideo y Colonia del Sacramento, la argentina Buenos Aires y, del otro lado del Atlántico, París y Burdeos se convierten en los ejes sobre los que giran unas narraciones centradas en la primera persona del singular. La incorporación de este correlato geográfico nos permitirá autenticar la dimensión autobiográfica en estos textos al observar procesos microhistóricos (individuales, subjetivos, endógenos) y macrohistóricos (colectivos, objetivos, exógenos) dentro de este corpus narrativo, y, además, esto permitirá repensar la relación existente entre este arco narrativo y la ficción del autor uruguayo.

Palabras clave: Autobiográfica; cartografía; espacialidad; Levrero; Schlögel.

\section{Mario Levrero's Writing Like an Hutobiographical and Literary Cartography, between the Río de la Plata and France}

\section{Abstract}

This paper realizes an analysis of the autobiographical writing of Mario Levrero (1940-2004), through of spatiality and from theoretical perspective of Karl Schögel. We regard than: Apuntes bonaerenses, Diario de una canalla, El discurso vacío, La novela luminosa and Burdeos 1972

\footnotetext{
1 Procedencia del artículo: El artículo se desarrolló en la estancia posdoctoral del autor en el Centro Peninsular en Humanidades y Ciencias Sociales, de la Universidad Nacional Autónoma de México (CEPHCIS, UNAM), bajo la dirección del Dr. Adrián Curiel Rivera.
} 
constitute an autobiographical and literary cartography of The Rio de la Plata and transatlantic cities inside of the Levrerian work. Namely, insofar than the Uruguayan cities Montevideo and Colonia del Sacramento; the Argentinian Buenos Aires and in the other side of Atlantic, Paris and Bourdeaux, become the axes about which rotate narrations wrote in first person of the singular. The incorporation of this geographical correlate will allow us to authenticate the autobiographical dimension in these texts to watch microhistorical processes (individual, subjective, endogenous) and macrohistorical (collectives, objectives, exogenous) inside this narrative corpus. In addition, will allow us rethink the existing relationship between this narrative arc and fiction of the Uruguayan author.

Keywords: Autobiographical; cartography; Levrero; Schlögel; spatiality.

Recibido: 01 de junio del 2020. Aprobado: 13 de julio del 2020

Artículo de reflexión https://doi.org/10.25100/poligramas.v0i51.10795

\section{¿Cómo citar este artículo en MLH? - How to quote this article in MLH?}

Islas Flores, Mario César. "La escritura de Mario Levrero como una cartografía autobiográfica y literaria, rioplatense y trasatlántica" Poligramas 51 (2020): n. pag. Web. Fecha de acceso

(día, mes en mayúscula y abreviado, y año).

\section{La clasificación como un lugar}

En primer término, habría que indicar que la vinculación de la obra de Mario Levrero con la ciencia ficción, o, inclusive, la circunscripción exclusiva a ella, está motivada, como el propio autor uruguayo lo refirió en más de una ocasión, por la figura de Marcial Souto, su editor en Uruguay, Argentina y España, respectivamente, ya que el también traductor y escritor español tiene una relación preponderante con este subgénero literario (Courtoisie 25; Monestier 108; Bruno, Galione y Bonino 137; Souto, Tratar... 253-264; Levrero, Cuentos... 17-18). La ciudad (1970), la primera novela de Levrero, fue publicada por la pequeña editorial montevideana Tierra Nueva, dentro de la colección Literatura diferente. El lugar (1982), su segunda novela en orden de redacción y tercera en ser publicada fue acogida por la revista bonaerense El 
Péndulo, que privilegiaba en sus páginas a la ciencia ficción y a la literatura fantástica. Este par de obras serían incluidas dentro de la colección Mundos imaginarios de Plaza \& Janés (Levrero 1999; 2000) a finales del siglo pasado, junto a autores consagrados de la ciencia ficción como Philip K. Dick.

No es extraño, pues, que, a partir de la ponderación de los criterios editoriales referidos, existan estudiosos de Levrero que concedan una importancia mayúscula a la ciencia ficción dentro de su producción literaria (Martínez), o que, incluso, plantean una indistinción radical entre ambas: "la obra de Levrero es ciencia ficción porque la ciencia ficción y la literatura general no pueden separarse claramente" (Sanchiz 234). El escritor rioplatense reaccionó en varias oportunidades contra ese encasillamiento apelando a un proceso creativo cimentado en la introspección (Berti; Warley 29; Domínguez, Si lo que escribo... 51; Escanlar, Muñoz 59; Pereira 70), pero mucho más importante aún que ese autodeslinde es el consenso crítico en torno al fuerte componente autobiográfico de su escritura, a tal grado que La novela luminosa, publicada póstumamente en 2005, sería reconocida como uno de los títulos emblemáticos en lengua española de los últimos tiempos (Babelia).

Esa dimensión autobiográfica en la obra de Levrero está íntimamente relacionada con la espacialidad en Apuntes bonaerenses (2017), ${ }^{2}$ Diario de un canalla (2015), ${ }^{3}$ El discurso vacío (2019), La novela luminosa (2008) y Burdeos, 1972 (2015), pues en ellas la descripción de ciudades como Montevideo y Colonia del Sacramento (Uruguay), Buenos Aires (Argentina) y París y Burdeos (Francia) ocupa un lugar muy significativo. A partir de este vínculo entre el autor y su entorno, intentaré articular una reflexión que condense la forma en que la espacialidad se expresa bajo las modalidades de itinerarios, secuencias o desplazamientos, en virtud de que el escritor montevideano privilegia elementos propios de su urdimbre cotidiana argentina, uruguaya y francesa. Se trata, por tanto, de trascender ese lugar estrecho en el que ha sido situado Levrero como creador por la vía de restituir la originalidad de uno de sus registros escriturales en los que las coordenadas espaciales terminan por ubicarnos en una trama personal e íntima.

\footnotetext{
2 Recupero esta obra de la antología intitulada Noveno piso, publicada en México.

${ }^{3}$ A pesar de que recupero Diario de un canalla y Burdeos, 1972 de su edición conjunta de 2015, debido a que son textos autónomos los citaré por separado en atención al contexto original en que fueron redactados.
} 
La espacialidad será, pues, la variable fundamental que incorporaremos en el análisis del corpus bibliográfico anteriormente consignado, con la intención de corroborar su adscripción genérica a la autobiografía, pues consideramos que, como afirma Schlögel, "los lugares son testigos de fiar", mientras que, en cambio, "los recuerdos son elásticos. A tal punto que uno puede componer e inventar pasados: las biografías como construcciones ad libitum". No obstante, "los lugares no cooperan en eso: siempre han estado ahí, y ahí siguen cuando hace mucho que se ha ido quien los recuerda. Tienen una especie de derecho de veto" (364). E veto puede ser entendido, en el caso que nos ocupa, como un límite a los abusos que homogenizan los libros ya aludidos con la ficción levreriana y, de este modo, tergiversan una intencionalidad, un contenido y una estructura (Polleri 11; Bértolo 13; Gandolfo, Descripción... 158-163; Ricciardi; Cosse).

\section{La escritura del reconocimiento}

En 1985, Levrero se mudó a Buenos Aires por una aguda insolvencia económica que le impedía cubrir siquiera el alquiler de su departamento en Montevideo. De ese exilio forzoso, no obstante, emergió una pasión por la también porteña y austral capital argentina que quedará consignada en Diario de un canalla. La redacción de Apuntes bonaerenses inicia algunos meses antes que ese otro libro autobiográfico y llega a empatarse con su escritura, como lo confirman algunas de sus anotaciones. En su conjunto, este díptico bonaerense ejemplifica de un modo elocuente que las rupturas siempre poseen una dimensión espacial (Schlögel 364) y encarna también una reorientación en la obra levreriana, que se caracteriza por el protagonismo explícito de la primera persona del singular y por la relevancia adquirida por los espacios intramuros y extramuros.

A lo largo de los años, Apuntes bonaerenses ha quedado sumido en la marginalidad, a tal grado que se le ha descartado del conjunto de libros clasificados como autobiográficos dentro de la obra de Levrero (Siscar; Corbellini La trilogía...; El pacto...; Pardo). A mí, en cambio, me parece que dicho texto tiene una importancia fundacional en la medida en que Levrero establece en el un procedimiento temporal respecto a la escritura y perfila una mirada intramuros y extramuros que explora los recovecos de la cotidianidad y sus antípodas luminosas. Esta idea fungirá como la brújula que orientará el recorrido por la que considero la piedra angular de la narrativa autobiográfica levreriana. 
Las escasas y temporalmente caprichosas páginas de Apuntes bonaerenses inician a comienzos de 1986 y se dilatan hasta marzo de 1988. Al respecto, conviene tener en cuenta que este opúsculo representa el poco tiempo que Levrero pudo robarle a su intensa y calendarizada rutina laboral que le exigía publicaciones de juegos de ingenio y en la que encontró una bien remunerada fuente de trabajo, en otras palabras, fue redactado durante sus periodos vacacionales (Pereira 68). En la entrada inicial, la especificación de la fecha es lo que hace fijar la mirada y preguntarse por qué Levrero habría de preocuparse por consignar con cierta meticulosidad una fecha (en este caso, 3 de enero de 1986). No obstante, el contenido de esas líneas, sin duda, redujo la extrañeza inicial entre sus lectores más asiduos, toda vez que la impronta de Kafka pareciera inalterable, y, en primera instancia, aparece una puerta solo en apariencia cerrada y, por tanto, solo un obstáculo hipotético que, sin embargo, simboliza una frontera y prefigura una realidad enigmática tras ella. La oscilante voluntad del personaje y la prosa llana que ralentiza la acción y pareciera dibujar una circunferencia remiten a cualquiera de las novelas que conforman la Trilogía involuntaria (Apuntes... 9).

Empero, si Levrero documentó un infructuoso intento por representar literariamente una experiencia, el segundo registro sorprende ahora sí por la modulación de la voz del autor, más que por la consignación de otra fecha, así medie una distancia entre ambas anotaciones de poco más de nueve meses. El 7 de octubre de 1986 Levrero describe cómo, desde la banca de una plaza (se trata de la Plaza del Congreso que estaba muy próxima a su departamento), observa cómo son alimentadas las palomas por unas personas que compran un alimento que, a su juicio, son simples granos de maíz. Ese es el modus vivendi de un chico al que le calcula una edad de entre 13 o 14 años y al que le augura un futuro próspero, y, por último, establece una analogía entre palomas y mujeres, a partir de la mala impresión que le causan las primeras (Apuntes... 9-11). Apenas resulta perceptible una intención literaria en esas líneas en las que se impone una mirada atenta al entorno y la voz de un cronista que se siente impelido a describir, con cierto detalle, una situación en la que se vio inmerso por el simple hecho de hacer acto de presencia en el espacio público.

La capacidad de experimentar de nuevo el amor a una edad madura, en un verano intensamente caluroso, que pareciera simbolizar esa sensación de embriaguez, desequilibrio y alteración de la percepción a causa, precisamente, de ese sentimiento grandioso y, a la vez, desdichado, porque no obtiene ni pierde en definitiva a una mujer amada, sino que la va 
"obteniendo por pedazos" (Levrero, Apuntes... 12), es el tema de tres anotaciones (11-15). Especular sobre si se trata de otro esbozo literario trunco, o si en esos párrafos predomina más bien una proyección de la genuina soledad que por entonces estaba experimentado Levrero, me parece poco productivo de cara a la temática que sí parecía motivarlo a escribir con una mayor disciplina: la Plaza del Congreso (aludida con anterioridad).

En la entrada del 18 de enero de 1988, Levrero consigna la existencia de una nueva figura en el escenario privilegiado de su mirada extramuros:

Un viejo, que desafía al sol. Es robusto y aunque vive pobremente tiene una presencia noble, esa rara aristocracia espiritual que sólo he percibido en ciertas personas humildes (y que me hace sentir despreciable). (Una vez, este hombre me pidió un cigarrillo; la ciudad me había acorazado en una especie de indiferencia selectiva, cerrado a todo lo que no me interesara, y entonces no prestaba atención a estos pedidos; pero este hombre se me impuso con su actitud y su presencia; al darle el cigarrillo sentí que era yo quien estaba recibiendo algo. Le ofrecí otro y lo rechazó). Ahora lo veo en la plaza, todos los días, en las horas que el sol cae a plomo (Apuntes... 15).

La historia de su admiración y desencanto por este hombre se extenderá por dos apuntes más, y el último de los catorce que conforman el libro corresponde, específicamente, al ocaso de su héroe:

2.III.88 Ha caído mi ídolo. El Hombre que Desafiaba al Sol en la plaza sigue en la plaza y al sol, pero hoy se ha puesto un sombrero ridículo, de paja trenzada o su imitación en plástico, liviano, blando, femenino, con dibujos de flores en la trama del trenzado. Es cierto que él no ha perdido su dignidad y lleva el sombrero de modo natural y sin mostrar vergüenza; pero es evidente que la tragedia se ha transformado en comedia (Levrero, Apuntes... 21).

Lo que a Levrero quizá no le resultó evidente es que también en Buenos Aires había comenzado la transformación de su escritura, como lo dejan entrever, de forma un tanto inconstante, sus anotaciones sobre el deficiente servicio telefónico (Apuntes... 16), acerca de las características de los envases de la salsa kétchup (16) o su enfrentamiento con una invasora 
e indeseable araña en su departamento (19-20); inclusive, ese mea culpa condensado en los párrafos sobre la necedad y la sabiduría tiene un tono ético y estético contrastante con su forma habitual de escribir literatura (20-21). Diario de un canalla encarnará plenamente la metamorfosis iniciada en Apuntes bonaerenses.

\section{La escritura corrompida}

Entre el 3 de diciembre de 1986 y el 6 de enero de 1987, es decir, a lo largo de poco más de un mes, Levrero escribió una serie de notas que terminará por agrupar bajo el peculiar título de Diario de un canalla. En este libro pareciera tener una compulsiva necesidad de justificar ante sí mismo la canallada que representa el haber traicionado a la literatura a cambio de un empleo redituable. La culpa se intensifica porque ese pacto fáustico apenas le produce sufrimiento:

Debo confesar que me he transformado en un canalla; que he abandonado por completo toda pretensión espiritual; que estoy dedicado a ganar dinero, trabajando en una oficina, cumpliendo un horario; que ahora estoy escribiendo esto porque tengo unas vacaciones. Cierto que me hice un canalla como único recurso para sobrevivir, pero lo triste del caso es que me gusta lo que estoy haciendo, y sólo me cuestiono en ratos perdidos y sin mayor énfasis (19).

En Diario de un canalla al igual que en Apuntes... la dimensión urbana está representada por la megalópolis que es la capital de Argentina y toma cuerpo en la figura de un Levrero peatón, de un voyerista extramuros:

Estoy viviendo en una de las grandes ciudades más corrompidas del mundo -y que me gusta... Sí, me gusta la ciudad de Buenos Aires - especialmente ese olor particular que flota junto a las entradas del subte-; me gusta la calle Corrientes, la indiferencia, la angustia no siempre percibida que flota bajo un cielo que no se mira, entre los gigantescos edificios y sobre la ausencia del mar -y del amor (19-20).

Por tal motivo, considero equivocado leer a Diario de un canalla como una "escritura del confinamiento, del espacio cerrado" (Jiménez, párr. 2) o como el relato de un encierro (Premat, párr. 2), porque Levrero siempre mantendrá contacto con el mundo exterior, así sea a través 
de la mediación de ventanas y pasillos, y cuando decide apersonarse en el espacio extramuros este deviene en motivo de interrogaciones y autoconocimiento; por tanto, los calificativos de "pobre" y "vacía" que Julio Premat (párr. 2) atribuye a esa "exterioridad" son injustificados.

A Elvio Gandolfo tampoco le fueron asequibles el significado y el deslinde condensados en Diario de un canalla, y, por ello, comparte su genuino desconcierto: "no se sabe muy bien si lo que leemos es un diario íntimo, una serie de reflexiones, o un modo de contrabandear el peso de la 'confesión', recursos y hallazgos del mejor dibujo animado" (Gandolfo 259). Esta actitud dubitativa deja abierta la posibilidad del estatuto ficcional de Diario de un canalla, pero Felipe Polleri va más lejos y plantea la homologación plena de todos y cada uno de los textos levrerianos como ficciones: "Cualquiera de las Irrupciones podría ser intercalada en La novela luminosa sin el menor esfuerzo. Muchas de las Irrupciones podrían ser cuentos de La máquina de pensar en Gladys o fragmentos de sus primeras novelas o de las últimas" (11). En cambio, Carina Blixen sí capta el carácter dinámico y los distintos espesores que poseen las columnas periodísticas de Levrero (párr. 14), aunque por ahora solo se puede sugerir la lectura de su ensayo a manera de necesario contraste respecto a la afirmación de Polleri.

Un concepto de autoría en el que queda excluida la existencia de un registro que no sea el ficcional en la producción de Levrero compromete no únicamente la cabal comprensión de un libro en particular, sino la de un arco narrativo en su conjunto, pues, los textos de Levrero no son como engranajes perfectamente intercambiables de una máquina, sino que se asemejan más bien a las partes de un puzle que, aun en el momento de su perfecta unión, continúan preservando su unicidad y relieve. Estas piezas están configuradas en temporalidades diversas y responden a intenciones diferenciadas, como Levrero nos lo recuerda:

Uno va armándose el mundo en que quiere puede o acepta vivir, a partir de datos que va recibiendo desde que nace. Va armando un rompecabezas infinito, al que siempre se le pueden agregar, y de hecho se le agregan, nuevas piezas, incluso entre dos piezas que parecían perfectamente ajustadas: parecía que allí, justo allí, la imagen, o trozo de imagen, estaba completa; pero viene otra pieza y calza entre esas otras dos tan ajustadas, calza y cambia la significación de ese trozo de mundo, tal vez del mundo entero -de ese mundo que nos hemos creado o nos vamos creando mientras vivíamos (Irrupciones... 27). 
Omitir, pues, la factura diferenciada de esas piezas conduce a posicionamientos intelectual y éticamente hiperrelativistas que impiden observar la ostensible carga autobiográfica que toma forma a partir de la extensa recreación de una espacialidad y temporalidad concretas y verificables, tanto en Diario de un canalla como en el resto de los libros que integran el corpus autobiográfico levreriano.

No concibo, pues, a Diario de un canalla como un artificio literario, como un gesto con el que Levrero busca encubrir una disimulada ficcionalización bajo el ropaje autobiográfico, sino que lo considero un genuino desplazamiento respecto a su propia escritura literaria: "Pero no estoy escribiendo para ningún lector, ni siquiera para leerme yo. Escribo para escribirme yo; es un acto de autoconstrucción... No me fastidien con el estilo ni con la estructura: esto no es una novela, carajo. Me estoy jugando la vida" (25). Me parece auténtica esta bravuconada porque, como afirma Souto, Diario de un canalla es efectivamente un texto fundacional (Prologo 11), aunque no haya sido en él donde Levrero descubrió el procedimiento para darle forma a una obra de aliento autobiográfico, pues eso ya había tenido lugar, insisto, en el esbelto volumen de Apuntes bonaerenses, así fuera por escasos meses de diferencia. Mi exploración intentará establecer cuál fue la ruta seguida por el escritor uruguayo en su más extenso registro personal de la década de los ochenta.

La primera anotación en Diario de un canalla data del 3 de diciembre de 1986, es decir, pervive el procedimiento de datación ensayado en Apuntes bonaerenses, e, incluso, está enfatizado en la medida en que se incluye, más detalladamente, la mensurabilidad temporal en relación con el móvil de la escritura: "Han pasado más de dos años; casi tres desde que empecé a escribir aquella novela luminosa, póstuma, inconclusa; dos años, dos meses y unos días desde el día de la operación" (Levrero, Diario... 17-18). Aquel proyecto literario fallido se convertiría con el tiempo en La novela luminosa. No obstante, lo que importa aquí es la toma de conciencia de la naturaleza de la obra entonces en curso. Esta tuvo lugar un par de días después de aquellos párrafos iniciales y vino inesperadamente del exterior y no de un ejercicio introspectivo, y estuvo pautada tanto por las características de su vivienda como por un hecho meramente azarístico: a uno de los patios interiores de su departamento arribó la pequeña cría de una paloma (Levrero, Diario... 25-26) y esa intempestiva presencia fue interpretada como una señal positiva que enviaba el Espíritu en relación con la empresa escritural que había 
emprendido (26-27). A partir de entonces, el eje espacial sobre el que girará este ejercicio escritural será, esencialmente, una realidad intramuros:

Este apartamento, que elegí por ser de los pocos en Buenos Aires silencioso como una tumba y que me resultó tan lóbrego como una tumba, por la escasa luz natural que recibe, tiene dos patiecitos: uno, al que se accede por la puerta de la cocina, y donde suele tenderse la ropa, está separado de otros edificios contiguos por un muro enormemente alto, que imagino inescalable (y espero no equivocarme); a él se abren también las tres amplias ventanas del comedor, o living-comedor. El otro corre a lo largo de mi escritorio y del dormitorio contiguo a él (29).

La detallada descripción del departamento situado en la calle Rodríguez Peña y próximo al Congreso argentino ilustra la extraordinaria atención con que Levrero observaba su entorno más inmediato, así como la preocupación precedente de elegir un espacio óptimo para instalarse en la capital argentina. En el último patio referido fue donde quedó atrapado el pichón aún incapaz de volar, y este también había sido la prisión y tumba de un par de roedores cuya presencia; primero, fue interpretada como la encarnación de una podredumbre personal, pero que, en un segundo momento, habían llegado a conmover con sus hábitos al autor montevideano (Levrero, Diario... 30-31). Los animales aparecerán en Diario de un canalla relacionados de forma muy estrecha también con la realidad extramuros:

Fue aquella misma tarde primaveral en aquel mismo banco de la misma plaza cuando probablemente haya cobrado en mí el impulso definitivo la necesidad de seguir escribiendo; y de seguir escribiendo precisamente esto. Me imaginé a mí mismo escribiendo mi filosofía acerca de las palomas -en realidad, una larga diatriba-, pero también quería registrar una patética imagen que había descubierto junto a mi zapato izquierdo: la de una abeja. Ni más ni menos que una abeja, algo tan insólito en este mazacote de cemento como esos grillos solitarios que he detectado en minúsculos sectores cubiertos de pasto (36-37).

El contexto en que se da ese instante de revelación aparece ya descrito - sin la inclusión de la abeja y los grillos- en la entrada del 7 de octubre de 1986 de Apuntes bonaerenses (9- 
10) y aparecerá, posteriormente, en uno de los poemas que figuran al inicio de El discurso vacío (12), lo que reafirma la importancia de esta experiencia. Pienso que ese hecho, en modo alguno es fortuito y que, además, constata la íntima conexión en cuanto a la intencionalidad de ambas obras, con la singularidad de que Diario de un canalla incorpora, además del presente bonaerense, algunos segmentos temporales del pasado montevideano: la etapa previa en que Levrero fue intervenido quirúrgicamente para extirparle la vesícula, su internamiento hospitalario y su periodo de convalecencia (43-44).

Y, al igual que la señal que Levrero necesitaba para retomar la escritura vino del exterior, el punto final de Diario de un canalla tiene que ver también con ese interregno entre el afuera y la intimidad de su espacio representado por el patio interior de su departamento, pues de él partiría una segunda ave, un pequeño gorrión bautizado como «Pajarito». Cabe resaltar también el reencuentro con una enigmática mujer llamada Silvia, es decir, hay otro hecho externo interpretado también de forma simbólica que cierra la obra (Levrero, Diario... 79). Este final, sin ser abrupto, tampoco permite guardar sospechas fundadas acerca de una fabulación encubierta de forma premeditada, sino que más bien apuntala la idea de una inflexión significativa en la voz narrativa del autor, motivada tanto por la rememoración de una situación dolorosa como por los retos que le impuso Buenos Aires. Esta profunda impronta que el paisaje exterior deja en el paisaje interior del escritor rioplatense la tendré en mente al aproximarme a El discurso vacío.

\section{La escritura redimida}

La decisión de Levrero de retornar a Uruguay no estuvo enteramente determinada por la saturación laboral y la soledad afectiva que configuraron esa crisis anímica que se torna patente a lo largo de Apuntes bonaerenses y Diario de un canalla. La mudanza obedeció también a una motivación de índole económica, específicamente, a la transformación de la dinámica en las revistas en que había estado laborando (Saurio 158). Si los dos textos que dieron comienzo a un nuevo registro dentro de su obra llevan la marca bonaerense, El discurso vacío, por su parte, estará influido de forma decisiva por la radical transformación de su ritmo de vida en Colonia. Y será ahí donde la escritura, pensada como simple ejercicio manual, como reflejo y depositaria de una vacuidad intelectual y anímica, cobrará fuerza y vitalidad al vincularse con la experiencia luminosa y se erigirá como una escritura redimida. 
El discurso vacío principia un 22 de diciembre de 1989 y su último registro data del 22 de septiembre de 1991. Este es, pues, como Apuntes bonaerenses y como Diario de un canalla, un texto en el que la voz de Levrero se dilata sin demasiada constancia y en el que, a pesar de la extensión temporal abarcada, de nuevo, como en los dos casos anteriores, el ejercicio escritural no redunda en un libro voluminoso. La estipulación de la fecha es una marca textual que también estará presente en El discurso vacío, pero, a diferencia del par de títulos recién referidos, en este último Levrero incorpora una especie de prólogo conformado por una nota explicativa acerca de la naturaleza de su libro (7). A este preámbulo lo acompañan dos poemas y la narración de un sueño (7-14). ¿Estas adiciones justificarían entonces hablar de autoficción en vez de autobiografía, como lo proponen algunos autores para el caso de este texto y también para La novela luminosa? (Núñez 29-41; Montoya 11-17). Es imperativo abordar esta cuestión antes de proseguir el análisis de El discurso vacío.

En 1977, Serge Dubrovsky publicó Fils, una novela a la que en una entrevista calificaría como una "ficción de hechos estrictamente reales; si se quiere autoficción", en oposición a la autobiografía que, a su juicio, era "un privilegio reservado a los importantes de este mundo en el ocaso de su vida y en un bello estilo" (Genette, Umbrales 98). Cabe indicar que esta caracterización del discurso autobiográfico está enraizada en aquellos contextos sociales donde impera el analfabetismo y la escritura es una práctica reservada a la élite, y, por tanto, su validez no puede ser ecuménica. Por su parte, resulta pertinente resaltar que en todo caso la autoficción cómo práctica literaria fue gestada al margen de una teoría que la sustentara, es decir, de un programa estético plenamente consciente, como lo ejemplifica en lengua inglesa Henry Miller con sus novelas Trópico de cáncer (2010) y Trópico de capricornio (2009), publicadas en la década de los treinta. Los relatos de Charles Bukowski (2014), protagonizados por su alter ego Chinaski desde finales de los sesenta, y la narrativa gráfica de American Splendor, de Harvey Pekar, que se extendería desde 1976 hasta 2008 (2011-2013).

De cualquier modo, el cisma político representado por la demolición del Muro de Berlín, así como por la implosión de la URSS, pautaría una marcada proliferación de relatos en primera persona que no encuadran en la definición de Dubrovsky, pues, más que el recuento de una existencia, son la escritura en tiempo presente de las mutaciones de un yo anónimo que desea dejar constancia de su devenir en la doble temporalidad bisagra (cambio de siglo y milenio) que le ha tocado experimentar, como lo ilustra elocuentemente la obra de la escritora bielorrusa 
Svetlana Alexievich, a quien se le concedería el Nobel de Literatura en el 2015, y, como lo ejemplifica también, aunque con motivaciones muy particulares, la escritura autobiográfica de Levrero en la parte sur del continente americano.

A esa escritura comprometida con la verdad y enfáticamente politizada, la perspectiva autoficcional, ya bajo la batuta del posmodernismo, opuso una autorreferencialidad acérrima, circunscrita al universo textual y empleando al yo para producir un intrincado juego de espejos que ubica al lector en una vasta zona de perplejidad. En Retorno a Viena, el psicoanalista galo Roland Jaccard expresa con vehemencia este principio:

Incluso el lector más ingenuo sospecha que cualquiera que cuenta su vida la transforma inevitablemente en una novela, único modo de escapar de la mediocridad y la única vía de acceso a una verdad interior que no cesa de ocultarse. No tomamos forma y consistencia alguna sino hasta que nos convertimos en la ficción de una ficción, lo que implica una cierta inclinación y talento para el desdoblamiento, así como un tanto de crueldad (48-49).

A mi juicio, Levrero careció de esa inclinación y talento para el desdoblamiento que en el horizonte hispanoamericano sí es perceptible desde el inconmensurable y póstumo libro Museo de la novela de la eterna del argentino Macedonio Fernández (1996), y en décadas más recientes, por señalar solo un par de representativos ejemplos, en numerosos textos de César Aira (Las curas... 1998; El congreso... 2019) o Mario Bellatín (Underwood... 2004; Retazos... 2011). Pienso que los textos autobiográficos levrerianos se ubican, pues, en una lógica diferente al propiciar un diálogo más directo y límpido entre autor y lector, que, sin embargo, no está exento de omisiones motivadas por una autocensura de signo variable o por la simple y humana erosión que sufren los recuerdos a causa del tiempo, así se trate de una memoria inmediata, pues, las autobiografías y memorias, como lo recuerda Krzysztof Pomian, son "relatos de lo que les aconteció a sus autores, de lo que han sentido, vivido, visto, leído u oído en el pasado" (Sobre... 26).

A diferencia de la estrategia de ficcionalización del yo referida, la escritura autobiográfica nos permite percibir elementos de índole extratextual, "marcas de historicidad" (Pomian, Sobre... 27) que, a veces, son sutiles y discretas, pero que ocasionalmente son ostensibles, como, a mi juicio, lo es la espacialidad en los textos autobiográficos de Levrero, debido a la 
acusada proliferación de matices descriptivos que coronan la recreación de Buenos Aires, Colonia del Sacramento, Montevideo y Burdeos, y, además, por una implicación explícita del yo que evoca las distintas memorias de corto, mediano y largo plazo que constituyen la materia esencial de este arco narrativo, el cual encarna una geografía de los espacios intelectuales y emotivos más trascendentes para el escritor rioplatense.

En virtud de lo anterior, resulta fundado plantear que El discurso vacío es otro fragmento de la autobiografía levreriana, aunque redactado sin esa intención manifiesta que sí orientó la escritura de Diario de un canalla. Esto queda ilustrado en la propia rememoración de la génesis del texto, pues Levrero evoca que en un inicio se trataba solo de practicar ejercicios de caligrafía para mejorar la letra. Al paso del tiempo, dichos escritos se convertirían en un medio de interlocución constante con su mujer Alicia Hoppe, toda vez que su relación experimentaba las dificultades propias de rutinas diferenciadas con motivo de los trabajos que desarrollaban, ella como psicoterapeuta y Levrero como free lance elaborando crucigramas para una publicación extranjera, lo que le permitía estar la mayor parte del tiempo en casa:

Ahí escribía cosas que tenía que comunicarle, muchas protestas contra ella, indicaciones. Fueron acumulándose un montón de hojas durante año y medio. Al mismo tiempo nació un texto en el que escribía de cosas personales, pero ya con intención literaria, y terminó siendo la historia de un perro y un gato. Un día hice una limpieza del escritorio y me propuse quemar la montaña de ejercicios de caligrafía en la parrilla del fondo, donde hacíamos asados. Mientras las llevaba, el inconsciente me hizo leer una frasecita y dije: Ah, no, esto me interesa, lo voy a leer. Era una novela (Domínguez, Un escritor... 133-134).

En otro momento, Levrero afirmará que El discurso vacío no tiene una palabra de invención (Saurio 163) y en las propias páginas de este lo define como una "torpe sustitución de la literatura" (Levrero, El discurso... 25). Sin embargo, no me atendré a sus dichos oscilantes y hasta contradictorios y optaré por fijar la mirada en el contenido de la obra, así como en su nexo con Colonia, pues en esta localidad uruguaya el tiempo del autor montevideano se tornará esencialmente doméstico, ya que en aquel entonces estaba experimentando nuevos roles a nivel personal al asumir la paternidad de Juan Ignacio, hijo de su pareja (Campodónico 112) y, en tal sentido, la propia dedicatoria de El discurso vacío es elocuente (9). 
En el prólogo poético de El discurso vacío, Levrero describe la experiencia luminosa que nos visita fugazmente, esa mezcla de emociones y pensamientos que con gran dificultad podemos referir a través de la palabra o la escritura, pero cuya irrupción es imprescindible para colmar de sentido a nuestra existencia. Es algo que, a pesar de dilatarse en la memoria, jamás llega a convertirse en una conquista permanente, no se osifica como un recuerdo porque la experiencia luminosa trasciende toda dimensión temporal, tal y como se lee en uno de los poemas: "Aquello que hay en mí, que no soy yo, y que busco" (Levrero, El discurso... 11). El discurso vacío ahonda en esta dificultosa búsqueda de lo luminoso y asume el reto aún mayor de intentar representarlo por escrito en una temporalidad regida por el signo de un malestar espiritual y físico: "mi primavera personal consiste fundamentalmente en la toma de altas dosis de psicofármacos" (33), se lee en una de las anotaciones del libro. El reverso de esta negatividad es la dimensión mística y luminosa que el autor llega a entrever y que intenta representar escrituralmente.

En El discurso vacío, Levrero fijó, a modo de terapia, una cima por conquistar: una escritura vacua, una escritura cuya finalidad era el ejercicio en sí; la forma; la concentración para espaciar las letras, pero, una vez tras otra, el sentido recubre el ornamento grafológico y falla la "autoterapia" escritural (15), aunque esa narrativización (involuntaria) tampoco debería ser considerada como un ejercicio literario sencillamente porque se trata del experimento fallido de un literato. El discurso vacío es, en el fondo, un texto autobiográfico que tiene como punto culminante una situación exterior, pero que, en términos afectivos, es muy cercana: el agravamiento de la salud de la madre de Levrero y su posterior deceso (132). Acerca de la especificidad de este registro autobiográfico y estableciendo una separación con respecto al literario, Levrero anota:

Hay otras formas de escritura, llamémosle literarias, que nunca tuvieron esta carga 'mágica'. Era la escritura inspirada, la que hacía compulsivamente, la que venía predeterminada desde lo más profundo. En cambio cuando trato de tocar lo que llaman realidad, cuando mi escritura se vuelve actual y biográfica, resulta inevitable poner inconscientemente en juego esos misteriosos y muy ocultos mecanismos, los que al parecer comienzan a interactuar secretamente y a producir algunos efectos perceptibles (El discurso... 100). 
Y acompasados con esos mecanismos se encuentra el significado que Levrero atribuye a la irrupción de las aves:

Algo sucede con los pájaros. Sucedió en Buenos Aires, dos veces, y sucedió aquí en Colonia el año pasado cuando inicié una historia (la que después concluí, y después quemé en la estufa). Ahora, cuando me había desviado de la historia del perro, aparece dramáticamente un pájaro en la boca del perro. Estas cosas son desconcertantes y me complican, sobre todo por su carga simbólica. Siento como si de pronto las circunstancias me situaran de lleno en un tema que trato de eludir, un tema para el cual todavía no me siento maduro (El discurso... 72).

El perro Pongo, al que se hace referencia, era la mascota familiar y sería objeto también de otra reflexión parecida con motivo de la apertura de un recoveco en una cerca que separaba la vivienda de Levrero de un solar baldío, de tal forma que el perro pudiera ir agrandando paulatinamente ese espacio y saliera de casa para que disfrutara de una mayor libertad: "podría pensarse ese hueco que voy ensanchando progresivamente en el alambrado lindero, como un paralelo de otro hueco, psíquico, que voy ensanchando progresivamente con miras a alguna forma de libertad, no del perro sino mía" (Levrero, El discurso... 56-57).

La preponderancia que adquirirá la computadora en la vida cotidiana de Levrero durante su estancia en Colonia es otro de los efectos secundarios que comenzará a advertir en el curso de su autoterapia grafológica, pues, según el autor, esta habría desplazado al inconsciente como objeto cardinal de sus disquisiciones y, por añadidura, de su propia literatura (Levrero, El discurso... 32). Efectivamente, la interacción virtual comenzará a suplantar a las relaciones propiamente humanas; inicialmente, de forma paulatina y, algunos años más tarde, de forma casi absoluta cuando se instale nuevamente en la capital uruguaya.

Fuera del estado armónico en que lo ubicaba la computadora a Levrero, le exasperaba prácticamente todo de Colonia: la dificultad para obtener unas fotocopias (El discurso... 37), encontrar un terapeuta cuya cercanía afectiva no lo invalidara para poder tratarlo (113), la contaminación auditiva de algún camión parlante (27) o de la estación eléctrica próxima a la segunda vivienda que habitará en esa pequeña ciudad turística (134-135), pero especialmente le molestaba y derrotaba por completo su ánimo: "el clima de Colonia que es verdaderamente maligno y desorganiza el sistema nervioso" (41). 
El entorno es fundamental para Levrero y, en sus propias palabras, le resultaba imposible independizarse de él (El discurso... 60; La novela... 112), ya que cualquier "desajuste" en éste comprometía su psique (El discurso 130) y, por consiguiente, la mudanza en la que deberá participar dentro de la propia Colonia lo trastorna en demasía. La adquisición de una nueva vivienda por parte de su mujer se convertiría, pues, en motivo de un prolongado y cotidiano sufrimiento (El discurso... 95), porque este nuevo traslado forzoso intensificaba la condición de exiliado (El discurso... 114), que de por sí Levrero experimentaba desde su salida de Montevideo:

Después de más de treinta y cinco años de habitar el mismo edificio, en los últimos seis años ya me he mudado tres veces, y voy para la cuarta mudanza; esto, sin contar los numerosos pasajes por hoteles y casas de amigos y parientes, o una estadía de un mes en una casita aquí en Colonia. Son muchos cambios para un hombre que suele apegarse extremadamente a los lugares (El discurso... 114).

Lo anterior, nos permite formarnos una idea de la conmoción que entrañaba una nueva mudanza para un hombre que ha anclado casi su vida entera al puerto de Montevideo y, dentro de él, a su departamento de la calle Soriano, y que un día se vio inmerso en una serie de desplazamientos sobre los que apenas tenía control, ya fuera por un imperativo de orden económico o por una situación de índole afectiva. La analogía, por tanto, que Levrero establece entre el espacio que debía ser abandonado y la relación con su pareja emblematiza, a la vez, que pone en perspectiva esa añeja crisis personal: "Esta casa que hemos de dejar, está, metafóricamente, cayéndose a pedazos (y materialmente, casi diría que también lo está)" (El discurso... 114). La confesada predilección de Levrero por las casas abandonadas, demolidas y ruinosas, e, inclusive, invadidas por la naturaleza (El discurso... 120), adquiere, de cara a la situación que enfrentaba por aquella nueva y forzada mudanza, un tinte extraordinariamente irónico, pues la ruina real de su hogar solo le producía una enorme pesadumbre. Extraña de sobremanera que una persona tan empeñada en advertir y escudriñar la carga simbólica de los acontecimientos sea incapaz, en este caso, de establecer una relación elemental entre una situación real y una preferencia estética, pero, precisamente, esa incapacidad evidencia la fuerte implicación anímica que está en juego en ese relato en primera persona, porque, como lo recuerda Schlögel, "las biografías se pueden convertir en espejos de derrumbamientos" (364). 
La "marginación" (Levrero, El discurso... 145) intramuros que experimentará en la nueva casa se compensará en parte con el reinicio de sus paseos por el puerto, incorporados en una serie de buenos hábitos que Levrero se había propuesto observar para mejorar su salud física y mental (El discurso... 151). La espacialidad extramuros cobra hacia el final de El discurso vacío cierta relevancia, aun en la adversidad climática de Colonia, y será justamente en un paseo en el que el autor rioplatense advertirá una vitalidad que creía extinta por completo: "Hoy vi, hacia la caída del sol, el reflejo de unos rayos rojizos del sol en unos ladrillos de cerámica barnizada, y me di cuenta de que aún estoy vivo, en el verdadero sentido de la palabra, y de que aún puedo llegar a situarme en mí mismo" (168).

La última anotación y también el epílogo de El discurso vacío corresponden al 22 de septiembre de 1991 (164-169). No es una fecha determinada por el azar. Ese día, la madre de Levrero habría cumplido 78 años. Había fallecido apenas unas semanas antes, el 14 de agosto, justo en el aniversario luctuoso de quien había sido su esposo y padre de Mario Levrero. El cierre de El discurso vacío no es literario, la culminación de una reflexión acerca de la "forma" y del "fluir" del vacío, como se había propuesto el autor (47), sino profundamente personal. En su vuelta a Montevideo, su escritura intensificará aún más este registro íntimo, en la medida en que su espacio se tornará casi exclusivamente intramuros y prescindirá de las presencias de Alicia y de Juan Ignacio. De ello dará amplia cuenta el "Diario de la beca". ${ }^{4}$

\section{La escritura luminosa}

Levrero retornaría a la capital uruguaya para escribir uno de los libros más importantes en lengua española en el recién nacido siglo XXI y, sin duda, el más influyente para el destino postrero de su obra entera. La obtención de la beca de la fundación Guggenheim, en el año 2000, le permitiría retomar aquel proyecto literario que databa de mediados de la década de los 80; es decir que inició en aquellos días aciagos de enfermedad que precederían a su mudanza a Buenos Aires, tal y como el autor rememora en Diario de un canalla. Empero, Levrero escribiría entre el 5 de agosto de 2000 y el 2 de agosto de 2001, esencialmente, el "Diario de la beca", un texto de más de cuatrocientas páginas que, a manera de disciplina escritural, se impuso de cara al compromiso adquirido para concluir la redacción de La novela luminosa, pero

\footnotetext{
4 "Diario de la beca" es la parte inicial de La novela luminosa; no obstante, conserva autonomía respecto a la segunda parte propiamente literaria y abarca, además, la mayor parte del volumen, como se detallará más adelante.
} 
el esfuerzo escritural, en dicho sentido, se centraría apenas en la anexión de un apartado intitulado "Primera comunión" al escrito literario preexistente.

El discurso vacío como La novela luminosa está dedicado a personas cuya existencia, por distintos motivos, ha sido significativa en el itinerario vital de Levrero, con excepción de la mención: "a las Potestades", que, asegura el autor, le "han permitido vivir las experiencias luminosas" (7). La misteriosa carga contenida en tal dedicatoria es un preámbulo justo tanto para la parte autobiográfica del texto como para la parte propiamente ficcional, ya que en ambas estarán presentes, bajo modalidades distintas, experiencias que pueden ser situadas en un horizonte enigmático, incluso metafísico. Y en otro tenor, la breve nota, en la que se apela a la comprensión de aquellas instituciones o personas que pudieran sentirse agraviados por la forma en que son referidos a lo largo de la obra resulta significativa respecto a la carga autobiográfica autopercibida en ella (9).

Un prefacio adjetivado como histórico termina por completar el prólogo. En él se narra el origen nebuloso de La novela luminosa y, al respecto, se formulan dos hipótesis, pero más importante que el esclarecimiento del impulso original de aquellas páginas, me resulta la vinculación explícita de dicha escritura con un contexto: "Probablemente había de fondo una comprensión de que el fracaso de mi relato se debía a la falta de un entorno, de un contexto que lo realzara, de un clima especial creado con una gran cantidad de imágenes y de palabras para reforzar el efecto que la anécdota debía provocar en el lector" (15). El anhelo de un espacio propicio y estimulante para acometer la tarea que se había propuesto, gracias al apoyo de la beca Guggenheim, será un tópico constante en el "Diario de la beca", así como la edificación de un espacio textual capaz de contener esas experiencias concebidas como inenarrables.

Desde el primer registro, Levrero describe el acondicionamiento de su departamento de la calle Mitre, situado en un cuarto piso, con miras a encarar el trabajo literario que le aguardaba:

Una de las primeras cosas que hice con esta mitad del dinero de la beca fue comprarme un par de sillones. En mi apartamento no había la menor posibilidad de sentarse a descansar; hace años que organizo mi casa como una oficina. Escritorios, mesas, sillas incómodas, todo en función del trabajo -o juego con la computadora, que es una forma de trabajo. Hice venir al electricista y cambié de lugar los enchufes de la 
computadora, para poder trasladarla fuera de la vista, fuera del centro del apartamento (24).

Desplazar a la computadora era una estrategia para disminuir la compulsión que había desarrollado por la programación y el correo electrónico en Colonia, y, después, por los juegos (Levrero, La novela... 35; 47), y, finalmente, por su afición culpable a la pornografía (52; 7879). A lo largo de las páginas del "Diario de la beca" quedarán extensamente consignadas las múltiples e infructuosas luchas de Levrero contra la elusión virtual, contra esa fuga constante de la angustia difusa; esto es, de la ominosa presencia de un tiempo estéril, amorfo y opresivo, pues su labor creativa precisaba estar cimentada en una sólida base de ocio, en otras palabras, de un tiempo propio y significativo, colmado a nivel anímico y gratificante también desde el punto de vista del intelecto.

La adecuación del entorno también daría pie a un autoanálisis que convergía de lleno con el tono de las páginas que Levrero concebía entonces como simples ejercicios de calentamiento previos a la escritura propiamente literaria:

Trajeron del Bazar Mitré las mesitas que compré. Tuve un amago de preocupación cuando las vi. Metálicas, negras, bajas, para poner una junto a cada sillón. Para cenicero, libro, anteojos y café. ¿Me estaré volviendo frívolo? ¿Me he salvado todos estos años de la frivolidad sólo por ser pobre? Pero no; no quiero preocuparme por eso. Las mesitas eran necesarias, como eran necesarios los sillones. Estoy empezando, aunque tardíamente, a pensar en mí mismo. El tema del retorno, el retorno a mí mismo. Al que era antes de la computadora. Antes de Colonia, antes de Buenos Aires. Es la forma de poder acceder, creo yo, a la novela luminosa, si es que se puede (Levrero, La novela... 39).

Levrero reconfiguraba el espacio con la esperanza de acceder por fin al ocio anhelado y la consecuencia textual de dicha labor es el registro de esas "coreografías de infinitos movimientos acordados" (Schlögel 348), para recuperar, en un sentido amplio, la definición de itinerarios formulada por Schlögel, pues, me parece adecuado extrapolar esta idea al ámbito existencial del autor montevideano en la medida en que el cotidiano registro de sus acciones se asemeja a esas "actas de un movimiento sin el que se detendría a la mayor brevedad la rutina obvia de nuestra entera civilización" (348), como afirma el ensayista alemán, pues son 
"crónicas de la dominación del espacio, actas de los avances en acortar distancias y condensar espacio" (348). Entiéndase aquí: acortar la distancia existente entre la inspiración y el espacio textual reservado a la literatura.

La búsqueda de un tiempo y espacio propicios para escribir fue ardua y extenuante, y, al final, resultaría exitosa a través de un modo sorprendente. A las 5:01 a. m. del viernes 8 de septiembre, Levrero registra un descubrimiento de primer orden:

Lo primero fue ordenar los platos y cubiertos y demás enseres, adentro de una palangana, para sacarlos de la pileta y para facilitar el trabajo. Ya mientras estaba intentando ese orden comencé a tener un sentimiento agradable. Había apagado la computadora y mi mente ya no estaba metida en esas cosas. Empezaron a asomar pensamientos míos, o no sé de quién, pero quiero decir humanos. Recuerdos, reflexiones. Y mientras estaba sumergido en el trabajo de lavar los cubiertos y luego los plásticos y luego los platos, hice el descubrimiento: descubrí que eso, y no otra cosa, era el ocio que necesitaba (La novela... 108).

Posteriormente, Levrero extenderá la posibilidad de encontrar el ocio más allá de las labores domésticas, pero, igualmente, de una forma fortuita y regida por una necesidad real: "Leer no implica ocio. En cambio, salir a caminar, aunque sea con la finalidad de hacer compras, puede ser ocio -si está la disposición-. Debo recordar esto. Debo recordar esto" (La novela... 110). Lo paradójico de esta relevación es que sus consecuencias de orden práctico, en relación con la reescritura de La novela luminosa, fueron prácticamente nulas, pues, mientras que el "Diario de la beca" acrecentaría su volumen con más de trescientas nuevas páginas, "Primera comunión", el relato al que terminaría por circunscribirse el esfuerzo escritural de Levrero, motivado por el financiamiento de la beca, apenas sumaría un poco más de veinte (536-559). Quizá Levrero terminaría también por ponderar la valía de aquel texto en el que interpretaba al personaje protagónico y quizá también atisbó en él algo de esa ansiada luminosidad.

En su escritura autobiográfica, Levrero formula analogías entre situaciones pretéritas y las que enfrentaba en su día a día, y constantemente les atribuye un significado simbólico. Ese es, insisto, un rasgo distintivo con respecto a sus obras literarias. No obstante, como también señalé en otro momento, en ocasiones se ve rebasado por su presencia devenida en poiesis narrativa y no puede ver la correspondencia entre vida y escritura, como, por ejemplo, cuando 
le resulta imposible advertir que en sus textos redactados en primera persona existe, como en los de Maugham, un negativo: "Podría decirse que la mayor parte de su material literario es trillado, quizá trivial o más bien frívolo, pero para mi gusto se salva justamente por ese desdoblamiento del autor que le permite comentarse a sí mismo continuamente mediante ironías que van creando una especie de negativo de sus relatos" (Levrero, La novela 105).

Lo que sí advirtió y apuntó Levrero, apenas en la segunda entrada de su diario, es la problemática representada por la recepción posmoderna bajo cuya égida todo es susceptible de ser juzgado como un ejercicio ficcional, y, en retrospectiva, debemos resaltar que su comentario se convierte en una suerte de profecía cumplida:

Hoy también me desperté con la determinación de no releer lo que lleve escrito en este diario, al menos no con frecuencia, para que el diario sea diario y no una novela; quiero decir, desprenderme de la obligación de continuidad. De inmediato me di cuenta de que será igualmente una novela, quiera o no quiera, porque una novela, actualmente, es casi cualquier cosa que se ponga entre tapa y contratapa (Levrero, La novela... 26).

Hay que distinguir entonces, para comprender a cabalidad lo que está en juego en el penúltimo esfuerzo rememorativo de Levrero, entre la parte ficcional de La novela luminosa y el "Diario de la beca"; esta bitácora del yo, la más extensa en su travesía hacia sí mismo y que terminaría por ocupar el lugar de la literatura, pero que, simultáneamente, conservaría cierta cercanía con ella al devenir en un prisma a través del cual podemos observar, a un tiempo, la obsesiva búsqueda de la experiencia luminosa (Levrero, La novela... 13) y su contraparte, la angustia difusa (42). Sin embargo, a diferencia de lo que sucede en El discurso vacío, no existe en el "Diario de la beca" ningún corte intelectual o anímico que pueda redondear la voluminosa aproximación de Levrero hacia su interioridad. En las páginas de este último texto, Levrero confecciona, inclusive, un final hipotético que ejemplifica la propia imposibilidad de un cierre literario: se trata de la falsa y patética carta de un suicida (La novela 434).

Concebido como ejercicio escritural disciplinario, el "Diario de la beca" cobró autonomía y redireccionó el propósito inicial de Levrero. Lo que debería ser el umbral de la reescritura de un texto literario pretérito devino en escritura, en tiempo presente, dentro de la ya conocida tesitura del primer pronombre personal; no obstante, cierta ironía perdura y se extiende a lo largo de ese preámbulo personal hacia La novela luminosa, e, incluso, se retrotrae a los textos 
autobiográficos precedentes, pues, cuando Levrero se propuso no narrar, cuando aspiraba a una escritura huera de significación como una forma de autoterapia, terminó trascendiendo los límites autoimpuestos, llenando páginas con situaciones y experiencias literarias (como lo ilustra el prólogo de El discurso vacío), y, en cambio, cuando le resultaba imperativo acometer la tarea literaria no solo no lo consiguió, sino que colmó una impresionante cantidad de cuartillas con una escritura que, sin ser vacua, no alcanza en definitiva el rango ficcional.

La ironía suprema de La novela luminosa estriba, entonces, en que hacia el final de la vida de Levrero, justo cuando la mayor parte de las limitaciones de orden económico que había padecido estaban resueltas por el estipendio de la beca Guggenheim y se pudo erigir en soberano de su tiempo al invertir casi perfectamente el patrón sueño-vigilia y optar por la noche y las madrugadas como sustituto del tiempo diurno y solar, enfatizando con ello su vocación de "hombre lunar" (El discurso... 96), y cuando, además, vivía un romance con Chl (chica lista) y con la computadora, y aunque en no pocas ocasiones la relación con ambas se tornaba desdichada, especialmente con la segunda a causa de la conciencia remordida por no estar a la altura del compromiso contraído con la fundación estadounidense, casi podría afirmarse que Levrero ha cristalizado un sueño largamente anhelado que se expresa en su indiferencia ante el timbre del teléfono, en su entera libertad para desplazarse fuera de su departamento, sea para buscar novelas policiales de la colección Rastros por la avenida 18 de Julio o en la feria Tristán Narvaja, sea solo o acompañado por Chl o alguna alumna de ese taller literario (Villanueva 135-168) que, compensaba la enorme ansiedad que implicaba su organización, con la alegría que le producía la lectura de esos escritores que consideraba estupendos, y, por si fuera poco, Levrero comía lo que se le antojaba a la hora por él decidida y había vencido al bochorno veraniego gracias a la adquisición de un equipo de climatización, lo que le permitía un tiempo sosegado en el que podía concentrarse en la lectura y en escribir.

Después de ese fracaso literario o del triunfo de la escritura autobiográfica -tal y como yo lo aprecio-, Levrero aún tendría tiempo para ensayar la edificación de su yo mediante la rememoración de un pasado remoto y trasatlántico en Burdeos, 1972.

\section{La escritura del insomnio}

El 5 de septiembre de 2003 a las 3:18 a. m., Levrero registra la primera entrada de Burdeos. Falta poco menos de un año para que fallezca y él viene presintiendo su muerte, ya desde la 
redacción de La novela luminosa. Los diversos malestares físicos y los trastornos de ansiedad han ido acentuándose por su sedentarismo. En Burdeos rememora, desde el insomnio, aquella aventura trasatlántica motivada por el amor de Antoinette, una francesa que había conocido en Montevideo, en el marco de un evento organizado por la Alianza Francesa. Esa constante y acentuada prolongación de la vigilia en el último año de su vida se convierte en parte constitutiva de un texto que, a consecuencia de ello, es, por partida doble, una escritura desde y sobre el insomnio:

Me quedo leyendo en la cama hasta que me viene el sueño; actualmente (estoy hablando de Montevideo, 2003) el sueño me viene cada vez más tarde. Suele ser alrededor de las seis de la mañana cuando dejo de lado el libro y me dispongo a dormir. Pero, en los últimos cuatro o cinco días, no me duermo. Fue hace tres días, creo, que me vinieron las imágenes de Burdeos, 1972; y empecé a escribirlas (Burdeos... 83).

En la época que Antoinette conoció a Levrero, ella trabajaba en la Embajada de Francia en Uruguay, y estaba por retornar a su país, específicamente, a Burdeos (Souto, Prologo 8), en donde se desempeñaría como profesora de un liceo. Una de las temáticas recurrentes de la prosa autobiográfica levreriana son las peripecias en torno a la búsqueda y arrendamiento de un espacio y su posterior adecuación, y Burdeos no es la nota discordante en tal sinfonía: "Habíamos alquilado un apartamento y necesitábamos, entre otras cosas, un reloj de cocina a pila, de esos que se cuelgan en la pared como un cuadro" (85). Aquella búsqueda los conducirá a una negociación en la que Levrero, según recuerda, advirtió la existencia de un "patrón" (85) que regía el aspecto y la conducta de los bordeleses. Esta captación de la alteridad será uno de los rasgos que caracterizarán a este libro.

Puede resultar un tanto sorprendente el detalle con que Levrero evoca la ubicación y las características del que será su hogar con Antoinette en Burdeos, teniendo en cuenta las poco más de tres décadas que lo separaban de aquellos eventos; empero, a mi juicio, la minuciosidad de la descripción solo muestra una vez más la sincera importancia concedida al espacio intramuros y también al entorno extramuros más inmediato y próximo:

Nuestro apartamento estaba en el cuarto piso, sin ascensor, de un edificio ubicado en una mansión próxima al río Garonne y, desgraciadamente, al puerto. Uno de los lados 
de esa manzana, el más cercano al río, daba a una amplia avenida asfaltada, o más bien ruta, por la que transitaban grandes camiones a toda hora del día y de la noche. Y en la manzana de enfrente, justo en la esquina de nuestra calle y la ruta, estaba el "Café des routiers", el café de los camioneros. Era un local no muy grande, con pocas mesas y un largo mostrador; estaba limpio y era cómodo y alegre (Levrero, Burdeos... 91).

Quizá en ninguno otro de sus textos autobiográficos aparezca con mayor fuerza la necesidad de ubicarse espacialmente que en Burdeos y ello resulta perfectamente lógico de cara a la radicalidad de la experiencia de conocer por vez primera un país europeo que, a diferencia de Argentina, apenas si guardaba algún parecido con respecto a Uruguay: "No tengo ningún plano de Burdeos. Cuando me instalo en alguna ciudad desconocida, comprar un plano de la ciudad me resulta indispensable" (97). En uno de sus artículos periodísticos, Levrero apunta algo que puede ser leído como una especie de poética sobre habitar el espacio que condensa su imperativa necesidad de orientación cartográfica:

Pienso que hay pequeños trozos de mundo que, a lo largo de nuestra vida y a fuerza de recorrerlos, vamos incorporando como algo conocido, aunque en realidad no lo son. Solo hemos aprendido a movernos por ciertos lugares con mayor facilidad que por otros; somos como murciélagos que chillan en la noche permanente de su ceguera y solo perciben del mundo el rebote de esos chillidos (Irrupciones... 53).

Montevideo fungirá, más que en ocasiones anteriores, como ese rasero espacial, como ese chillido con el que Levrero intentará situarse y atenuar la alteridad estableciendo, por ejemplo, analogías entre cierta feria bordelés de mercaderías y la de Tristán Narvaja (Levrero, Burdeos... 99) o entre el Parque Rodó de la capital uruguaya y el jardín público de la localidad francesa (171). En Burdeos hasta la contemplación de la luna, de una luna diferente a la que conocía como resultado de haberla contemplado siempre desde la parte sur del continente americano, patentizará su condición de extranjería (102). Y hasta lo que pudo haberle restituido cierta paz interior, la naturaleza portuaria que Burdeos compartía con su ciudad natal, devino en una tortura nocturna (103).

Los mecanismos de la memoria son arbitrarios. La rememoración de Levrero es extraordinariamente detallada para ciertas cuestiones que podríamos considerar menores de su 
estadía en Burdeos, pero otros elementos nodales de su propia vida familiar se le escapan por entero. Esto es así porque toda "memoria privada, igual que la pública, está abierta a su 'sobreescritura', cambio, fracturación, bloqueo o reinterpretación" (González 501). Al no tener esto en cuenta, Carolina Bartalini plantea que, en Burdeos, Levrero arriba a la "indiscernibilidad entre ficción y experiencia, entre pasado y presente y entre la literatura y la vida" (párr. 2).

Levrero tiene perfecta conciencia de los límites de su rememoración y Burdeos posee por ello el rasgo distintivo de lo involuntario, pues es una captación que se da en esa especie de duermevela configurada por el agravamiento de ciertos trastornos de ansiedad y digestivos, y por la propia medicación que Levrero tomaba para conciliar el sueño:

Cuando los recuerdos no se presentan espontáneamente, y tengo que buscarlos, no es mucho lo que encuentro y, por lo general, en esos recuerdos yo estoy a solas. Es que en Francia, tanto en Burdeos como en París, yo estaba solo la mayor parte del tiempo, o como si lo estuviera. Salvo durante la noche, en Burdeos, con Antoinette durmiendo o sonambuleando a mi lado. Creo que cuando despertaba de mañana, ya estaba solo; ¿pero dónde estaría Pascale? (Burdeos... 115).

El desajuste emocional sufrido por Levrero en territorio francés lo llevaría a experimentar deseos suicidas (Levrero, Burdeos... 105-106). Sin embargo, a medida que su residencia en Burdeos se extendió, la perfecta asimilación del idioma francés lo trastornará, irónicamente, mucho más que la extrañeza experimentada en un inicio, y este terror a perder por completo su personalidad aunado a la crisis en que se sumió su relación con Antoinette y con Pascale serían las causas determinantes que pondrían punto final a su más aventura europea y, a más de treinta años de distancia ese pasado distante sería el colofón de su escritura autobiográfica y de su propia vida. 


\section{H modo de conclusión: la escritura como una cartografía intelectual y anímica}

La escritura autobiográfica cultivada por Mario Levrero en Apuntes bonaerenses, Diario de un canalla, El discurso vacío, La novela luminosa y Burdeos, 1972, es indisociable de espacialidades concretas, tanto a nivel de intramuros como extramuros, situadas en las ciudades de Buenos Aires, Colonia del Sacramento, Montevideo y Burdeos, y, en su conjunto, conforman una cartografía autobiográfica y literaria rioplatense y trasatlántica que nos sirve de guía para ubicarnos en el incesante y complejo proceso creativo del escritor uruguayo. Sin el abordaje crítico de este binomio constituido por la espacialidad y la temporalidad, no es posible dimensionar la genuina apuesta personal contenida en este arco autobiográfico, a saber: la edificación de un espacio íntimo en el que toda actividad estaba supeditada a encontrar ese ocio que a Levrero le resultaba imprescindible para sobrellevar la angustia difusa y poder, de ese modo, escribir.

Los textos autobiográficos levrerianos constituyen un autoanálisis irónico, nada solemne y por momentos humorístico y hasta autocompasivo, pero vinculado siempre a su deteriorado y precario departamento montevideano de la calle Soriano, que rememorará nostálgicamente en Diario de un canalla; a su espacioso y bien equipado departamento ubicado en la calle Rodríguez Peña, cercano al Congreso argentino, y a esa plaza que será fundamental en su impulso autobiográfico inicial; al par de viviendas que compartió con Alicia Hope y su hijo Juan Ignacio en Colonia del Sacramento, en las que su escritura se redimiría de la canallada pretérita consignada en Diario de un canalla, por mediación de aquella inusitada autoterapia grafológica que finalmente se metamorfosearía en El discurso vacío; a su departamento de la Calle Mitre, en el que intentaría cumplir a cabalidad con el compromiso contraído con la fundación

Guggenheim, reescribiendo La novela luminosa, pero en donde, a su pesar y con una intensa conciencia del fracaso, terminaría redactando una vez más su vida en tiempo presente en "Diario de la beca", un texto que, a la postre, sería reconocido como uno de los más importantes escritos en lengua castellana en la transición de entresiglos. Por un azar afortunado, esta última morada uruguaya se encontraba también en un cuarto piso, al igual que aquel otro departamento compartido con Antoinette y Pascale del otro lado del Atlántico, en Burdeos; 
aquella osadía viajera y drama amoroso articulados como una escritura desde y sobre el insomnio en el penúltimo año de la vida de Levrero.

Los itinerarios emprendidos por las librerías bonaerenses de Corrientes, o por las ubicadas en la avenida 18 de Julio, en la capital uruguaya, o por Colonia, para zanjar cuestiones relacionadas con su trabajo, o por Burdeos, para conseguir revistas y discos, o por los bazares montevideanos, con miras a equipar su departamento de la calle Mitre en su definitivo retorno a Montevideo, se complementan con rutinas y manías en el espacio intramuros en el que Levrero se refugia del frío atenazante o del calor y humedad insufribles, y en el que, a pesar de sus esfuerzos, termina padeciendo siempre la incesante contaminación auditiva; pero, aun en ese espacio privado e íntimo, la interacción con el mundo exterior continúa mediante la computadora o a través de las ventanas desde las que observa palomas, gorriones, perros y roedores que se convertirán en símbolos de su ánimo y encarnarán también algunos de sus miedos a lo largo de sus libros redactados en la primera persona del singular.

Cabe señalar, por último, que, a diferencia de sus novelas y cuentos, los textos autobiográficos de Levrero están configurados a partir de los límites que impone la vida cotidiana, y esto se refleja en la compulsiva necesidad de consignar fechas y horarios en los que se efectúan o a los que se refieren dichos ejercicios escriturales, y, de forma igualmente visible, en la imposibilidad de un final inventado, producido de forma intencional para coronar un libro. Finalmente, una cualidad distintiva de estos libros es esa especie de negativo, de explicación que los acompaña bajo las modalidades de analogías directas entre un pasado reciente o distante con respecto a una situación presente o como un paralelismo simbólico representado por las presencias fugaces o perdurables de abejas, aves, perros o roedores, interpretadas de forma esperanzadora o negativa.

\section{Coda}

En la parte última de su colosal indagación acerca de la indisolubilidad entre espacio y tiempo, Schlögel se pregunta por el tipo de reflexiones que el Moscú del siglo pasado y Los Ángeles del siglo XXI motivarían en Heródoto y Walter Benjamin:

¿Qué se pondrían a hacer los maestros de una percepción histórica de tal riqueza y complejidad como la suya, puestos en los lugares históricos del siglo XX o del XXI? ¿Qué 
podría aprenderse de ellos, pero también de literatura, arte y cinematografía, de cara a encontrar un lenguaje a la altura de la época? ¿Quizás cupiera hallar respuestas a la pregunta de cómo escribir uno grandes narraciones tras el fin de la gran narrativa? (18).

Quizás las obras autobiográficas de Levrero, insertas en la temporalidad de entresiglos y enraizadas en zonas históricas periféricas (si nos atenemos a la caracterización históricoespacial de Schlögel), podrían constituir una respuesta alternativa a la interrogante formulada por el estudioso alemán. ¿De qué se puede escribir tras el colapso de las grandes narrativas? ¿De un exilio forzado por la precariedad y agravado por una salud física y mental frágiles, y por la conciencia remordida por, a pesar de todo, encontrar placer en un nuevo modus vivendi en una urbe percibida como corrupta? ¿Del resquebrajamiento de una relación amorosa en un entorno intramuros y extramuros en el que se experimenta un gran malestar físico y anímico? ¿De un aislamiento acérrimo atenuado ocasionalmente por humanos destellos afectivos y también por la elusión cibernética y los psicofármacos? ¿De tortuosas e inexorables mudanzas? ¿Del clima insufrible y la incesante contaminación auditiva? ¿De la enfermedad y la muerte de los padres? ¿Del registro múltiple y meticuloso de la vacuidad? ¿De esta improductividad literaria que se verifica en un espacio construido expresamente para que acaeciera exactamente lo contrario, pero en el que, contra todo pronóstico, emerge una extensa cartografía de un yo agazapado por igual en el presente más inmediato como en el pasado remoto y fragmentado, e, inclusive, atisbado en el insomnio, en una duermevela inacabable? Quizás. 


\section{Referencias}

Aira, César. El congreso de literatura. México: Era, 2019. Impreso.

Aira, César. Las curas milagrosas del doctor Aira. México: Era, 1998. Impreso.

Babelia. "25 años en 100 libros". El País. Web. 28 oct. 2016 <https://elpais.com/cultura/2016/10/28/babelia/1477661801_804300.html>.

Digital.

Bartalini, Carolina. "Burdeos. Gestos de contemporaneidad". Cuadernos LIR/CO. Web. 07 jun. 2016 <http://journals.openedition.org/lirico/2230>. Digital.

Bellatín, Mario. "Retazos ensangrentados de un reino inexistente". Elias Canetti. Una luz sobre la cabeza: Narrativa austríaca postkafkiana. México: Vanilla Planifolia, 2011. 12-17. Impreso.

Bellatín, Mario. "Underwood portátil modelo 1915". Fractal. Ene.-Mar. 2004: 103-140. Impreso.

Berti, Eduardo y Jorge Warley. "La literatura es como las palabras cruzadas". Mario Levrero: Un silencio menos. Comp. Elvio Gandolfo. Buenos Aires: Mansalva, 2013. 27-32. Impreso.

Bértolo, Constantino (Prólogo). París. Por Mario Levrero. Barcelona: DeBolsillo. 2010. Impreso.

Blixen, Carina. "Irrupciones: el escritor en < traje y corbata >". Cuadernos LIR/CO. Web. 07 jun. 2016 <http://journals.openedition.org/lirico/2218>. Digital.

Bruno, Juan Antonio et al. "Un tercer estado". Mario Levrero: Un silencio menos. Comp. Elvio Gandolfo. Buenos Aires: Mansalva, 2013. 136-144. Impreso.

Bukowski, Charles. Escritos de un viejo indecente. Trad. J. M. Álvarez Flórez y Ángela Pérez. Barcelona: Anagrama, 2014. Impreso.

Campodónico, Miguel Ángel. "Tengo ganas de dejar a Levrero de lado". Mario Levrero: Un silencio menos. Comp. Elvio Gandolfo. Buenos Aires: Mansalva, 2013. 110-117. Impreso.

Corbellini, Helena. El pacto espiritual de Levrero. Montevideo: Paréntesis Editorial. 2018. Impreso.

Corbellini, Helena. "La trilogía luminosa". Revista de la Biblioteca Nacional. Web. 2011 <http://bibliotecadigital.bibna.gub.uy:8080/jspui/handle/123456789/31882?mode= full>. Digital 
Cosse, Rómulo, "Levrero: del relato breve a La novela luminosa". Caza de Levrero: asedios críticos a la obra de Mario Levrero. Comps. Graciela Franco, María del Carmen González y Patricia Núñez. Montevideo: Rebeca Linke Editoras, 2015. 103-114. Impreso.

Courtoisie, Rafael. "El texto preexistente". Mario Levrero: Un silencio menos. Comp. Elvio Gandolfo. Buenos Aires: Mansalva, 2013. 24-26. Impreso.

Domínguez, Carlos María. "Si lo que escribo puedo ayudar a alguien creo que mi vida está más que justificada". Mario Levrero: Un silencio menos. Comp. Elvio Gandolfo. Buenos Aires: Mansalva, 2013. 47-54. Impreso.

Domínguez, Carlos María. "Un escritor en los paraísos virtuales de la imaginación”. Mario Levrero: Un silencio menos. Comp. Elvio Gandolfo. Buenos Aires: Mansalva, 2013. 132135. Impreso.

Escanlar, Gustavo y Carlos Muñoz. "Levrero o los modos del hipnotismo". Mario Levrero: Un silencio menos. Comp. Elvio Gandolfo. Buenos Aires: Mansalva, 2013. 55-67. Impreso. Fernández, Macedonio. Museo de la novela de la Eterna. Madrid: UNESCO, 1996. Impreso. Gandolfo, Elvio. "Descripción de un combate. Sobre La novela luminosa". Caza de Levrero: asedios críticos a la obra de Mario Levrero. Comps. Graciela Franco, María del Carmen González y Patricia Núñez. Montevideo: Rebeca Linke Editoras, 2015. 158-163. Impreso.

Gandolfo, Elvio. "Diario de un canalla (1992)". La máquina de pensar en Mario: Ensayos sobre la obra de Levrero. Ezequiel de Rosso (selección y prólogo). Buenos Aires: Eterna Cadencia, 2013. 256-259. Impreso.

Genette, Gérard. Umbrales. Trad. Susana Lage. México: Siglo XXI Editores, 2001. Impreso.

González, María de Jesús. "Raymond Carr: la biografía de un historiador". La historia biográfica en Europa: Nuevas perspectivas. Eds. Isabel Burdiel y Roy Foster. Zaragoza: Institución Fernando el católico/Diputación de Zaragoza, 2015. 491-518. Impreso.

Jaccard, Roland. Retorno a Viena. Trad. Guillermo de la Mora. México: Editorial Moho, 2016. Impreso.

Jiménez Morato, Antonio. "La odisea domiciliaria". Revistapenultima.com. Web. 26 abr. 2020 <http://revistapenultima.com/la-odisea-domiciliaria-por-antonio-jimenez->. Digital.

Levrero, Mario. Cuentos completos. Barcelona: Literatura Random House, 2019. Impreso.

Levrero, Mario. El discurso vacío. Barcelona: DeBolsillo, 2019. Impreso. 
Levrero, Mario. "El lugar". Revista El péndulo. Ene. 1982: 97-149. Impreso.

Levrero, Mario. La ciudad. Montevideo: Tierra Nueva, 1970. Impreso.

Levrero, Mario. La novela luminosa. Barcelona: Random House Mondadori, 2008. Impreso.

Levrero, Mario. Noveno Piso. Guadalajara, México: Impronta Casa Editora, 2017. Impreso.

Miller, Henry. Trópico de cáncer. Trad. Carlos Manzano. México: Punto de lectura, 2010. Impreso.

Miller, Henry. Trópico de capricornio. Trad. Carlos Manzano. Barcelona: Edhasa, 2009. Impreso.

Monestier, Felipe. "Levrero, el inconsciente". Mario Levrero: Un silencio menos. Comp. Elvio Gandolfo. Buenos Aires: Mansalva, 2013. 106-109. Impreso.

Montoya, Jesús. Mario Levrero para armar: Jorge Varlotta y el libertinaje imaginativo. Montevideo: Trilce, 2013. Impreso.

Núñez, Matías. "Autoficción e intertextualidad en Mario Levrero. La escritura como performance". Escribir Levrero: Intervenciones sobre Jorge Mario Varlotta Levrero y su literatura. Ed. Carolina Bartalini. Buenos Aires: Eduntref, 2016. 29-41. Impreso.

Pardo, María Cecilia. "La zoología de los textos autorreferenciales de Mario Levrero". Escribir Levrero: Intervenciones sobre Jorge Mario Varlotta Levrero y su literatura. Ed. Carolina Bartalini. Buenos Aires: Eduntref, 2016. 59-69. Impreso.

Pekar, Harvey. American Splendor. Barcelona: Ediciones la cúpula, 2011-2013. Impreso.

Pereira, Luis. "Yo nunca he escrito nada que no haya vivido". Mario Levrero: Un silencio menos. Comp. Elvio Gandolfo. Buenos Aires: Mansalva, 2013. 68-73. Impreso.

Polleri, Felipe. "Me acuerdo". Irrupciones. Por Mario Levrero. Buenos Aires: Criatura Editora, 2013. 7-12. Impreso.

Pomian, Krzysztof. Sobre la historia. Trad. Magalí Martínez Solimán. Madrid: Cátedra, 2007. Impreso.

Premat, Julio. "Las puertas de Levrero". Cuadernos LIR/CO. Web. 07 jun. 2016 <http://journals.openedition.org/lirico/2269>. Digital.

Ricciardi, Charles. "Los (re)pliegues del discurso (vacío)". Caza de Levrero: asedios críticos a la obra de Mario Levrero. Comps. Graciela Franco, María del Carmen González y Patricia Núñez. Montevideo: Rebeca Linke Editoras, 2015. 147-157. Impreso. 
Sanchiz, Ramiro. "Inventos de editores. Tensiones entre Mario Levrero y la ciencia ficción". Escribir Levrero: Intervenciones sobre Jorge Mario Varlotta Levrero y su literatura. Ed. Carolina Bartalini. Buenos Aires: Eduntref, 2016. 223-235. Impreso.

Saurio. "Espacios libres". Mario Levrero: Un silencio menos. Comp. Elvio Gandolfo. Buenos Aires: Mansalva, 2013. 150-168. Impreso.

Schlögel, Karl. En el espacio leemos el tiempo: Sobre Historia de la civilización y geopolitica. Trad. José Luis Arántegui. Madrid: Siruela, 2007. Impreso.

Siscar, Cristina. "Levrero personaje o la creación de sí mismo. Sobre los diarios de Mario Levrero". Escribir Levrero: Intervenciones sobre Jorge Mario Varlotta Levrero y su literatura. Ed. Carolina Bartalini. Buenos Aires: Eduntref, 2016. 185-191. Impreso.

Souto, Marcial. "Tratar con Jorge Varlotta para publicar a Mario Levrero. Treinta años de adrenalina editorial". Escribir Levrero: Intervenciones sobre Jorge Mario Varlotta Levrero y su literatura. Ed. Carolina Bartalini. Buenos Aires: Eduntref, 2016. 253-264. Impreso.

Souto, Marcial. "Prólogo". Diario de un canalla. Burdeos, 1972. Por Mario Levrero. Barcelona: Random House, 2015. 7-13. Impreso.

Villanueva, Liliana. Maestros de la escritura. Buenos Aires: Godot, 2018. Impreso 